\title{
A Public Health Ethics Approach to Non-Communicable Diseases
}

\author{
Stacy M. Carter • Lucie Rychetnik
}

Received: 5 December 2012 / Accepted: 16 December 2012

(C) Springer Science+Business Media Dordrecht 2013

Keywords Public health ethics $\cdot$ Non-communicable disease $\cdot$ Obesity

Although bioethicists have written about public health problems for many decades (e.g., Faden and Faden 1978; Bayer and Moreno 1986), public health ethics as a distinct field is not much older than the Journal of Bioethical Inquiry (JBI) itself. Around 2000, there was a rapid increase in the number of ethicists writing about public health problems (e.g., Kass 2001; Upshur 2002) as well as engagement of public health practitioners with ethical dilemmas and questions (e.g., Thomas et al. 2002; Jennings et al. 2003). Public health ethics has tended to focus on communicable diseases, pandemics, contagion, and crises. This is not surprising given the acute problems they raise, not least questions regarding coercion and harm to others. However, in public health policy and practice, there is increasing attention to the significance of non-communicable diseases. This

S. M. Carter $(\bowtie) \cdot$ L. Rychetnik

Centre for Values, Ethics and the Law in Medicine

(VELiM), School of Public Health, University of Sydney,

Sydney, Australia

e-mail: stacy.carter@sydney.edu.au

L. Rychetnik

e-mail: lucie.rychetnik@sydney.edu.au

L. Rychetnik

Screening and Test Evaluation Program (STEP),

School of Public Health, University of Sydney,

Sydney, Australia concern was sufficient to stimulate the second only United Nations high-level meeting on a health issue in the history of that organization, held September 2011 in New York (United Nations Secretary-General 2011). This meeting produced official acknowledgement and agreement between member states that worldwide changes in prevalence of non-communicable diseases such as diabetes, cardiovascular disease, cancer, and respiratory illnesses are associated with particular kinds of development and that prevention of these diseases is an important global political and economic challenge.

The symposium in this issue of the $J B I$ engages with the relationship between public health ethics and noncommunicable diseases. Governments in developed countries have been particularly concerned with rising rates of obesity in populations when planning their responses to non-communicable diseases; thus, most authors in this symposium consider obesity in their contributions. Moreover, the $J B I$ has always published empirical, interdisciplinary ethical scholarship that is relevant to practice. This symposium is no exception, bringing together the perspectives of scholars and practitioners from a range of disciplines. The opening article, from Ross Upshur (2013), provides an introduction and overview. He examines the diversity of approaches within public health itself, relating these to the history and diversity of public health ethics. He concludes that an ecological and critical approach is needed to inform public health action on obesity and overweight.

The next two authors-Jan Deckers and Peter Sainsbury-provide some illustration of how this might be done. Deckers (2013) makes a provocative argument about the consumption of animal products. 
Although his conclusions are controversial, his approach models the kind of interconnectedness and attention to systems required to enact an ecological public health ethics. This includes recognizing that human health is an important telos, but not the only good about which we should be concerned. Peter Sainsbury (2013) draws on his extensive experience as a public health practitioner to provide a detailed account of how urban development works, illustrating the value, but also the complexity - and indeed the difficulty - of getting public health ethics into practice. He argues that for public health ethics to make a difference, it needs to engage effectively with political and social processes. Like Deckers, Sainsbury asserts the importance of connecting health and non-health outcomes, in this case extending health promotion into non-health sector domains.

Lenny Vartanian and Joshua Smyth (2013) remind us of the importance of empirical evidence in thinking well about ethical problems. Their research contributes to a growing body of evidence about the stigmatization of obese people and its effects on their wellbeing. From the earliest days of scholarship on public health ethics, a central concern has been the relation between populations and individuals: Vartanian and Smyth's article reminds us that interventions conceptualized and justified at the level of populations can do harm to individuals and that this potential for harm should be taken seriously.

This symposium adds to the body of work in the $J B I$, and in the broader ethics literature, on the moral dimensions of public health policy and practice. As governments are increasingly focused on intervening in populations to prevent and control non-communicable disease, there is a growing need for empirical, interdisciplinary scholarship that can provide useful ethical guidance. The authors in this symposium offer wide-ranging and stimulating perspectives on this challenge.

\section{References}

Bayer, R., and J.D. Moreno. 1986. Health promotion: Ethical and social dilemmas of government policy. Health Affairs 5(2): 72-85.

Deckers, J. 2013. Obesity, public health, and the consumption of animal products: Ethical concerns and political solutions. Journal of Bioethical Inquiry 10(1). doi:10.1007/s11673012-9411-x.

Faden, R.R., and A.I. Faden. 1978. Preface. Health Education and Behavior 6(2): 177-179.

Jennings, B., J. Kahn, A. Mastroianni, and L.S. Parker, eds. 2003. Ethics and public health: Model curriculum. Washington, DC: Health Resources and Services Administration, Association of Schools of Public Health, and The Hastings Center.

Kass, N.E. 2001. An ethics framework for public health. American Journal of Public Health 91(11): 1776-1782.

Sainsbury, P.G. 2013. Ethical considerations involved in constructing the built environment to promote health. Journal of Bioethical Inquiry 10(1). doi:10.1007/s11673-012-9423-6.

Thomas, J.C., M. Sage, J. Dillenberg, and V.J. Guillory. 2002. A code of ethics for public health. American Journal of Public Health 92(7): 1057-1059.

United Nations Secretary-General. 2011. Prevention and control of non-communicable diseases: Report of the SecretaryGeneral. New York: United Nations. http://www.un.org/ga/ search/view doc.asp?symbol=A/66/83\&Lang=E.

Upshur, R.E.G. 2002 . Principles for the justification of public health intervention. Canadian Journal of Public Health 93(2): 101-103.

Upshur, R. 2013. What does public health ethics tell (or not tell) us about intervening in non-communicable diseases? Journal of Bioethical Inquiry 10(1). doi:10.1007/s11673012-9422-7.

Vartanian, L.R., and J.M. Smyth. 2013. Primum non nocere: Obesity stigma and public health. Journal of Bioethical Inquiry 10(1). doi:10.1007/s11673-012-9412-9. 